\title{
Manufacturing Innovation and Horizon 2020
}

\author{
Erastos Filos \\ European Commission, DG Research and Innovation, Brussels, Belgium \\ erastos.filos@ec. europa.eu
}

\begin{abstract}
A current trend in crisis-laden Europe is de-industrialisation. The European Union has launched ambitious policies and proposed a new research and innovation framework programme, Horizon 2020, to counter this trend and to foster innovation in manufacturing. The paper highlights the key issues related to this upcoming programme. $R \& D$ and innovation efforts, however, need to be underpinned by smart policies that in particular link up relevant $R \& D$ and innovation strategies at regional, national and European level and offer incentives for growth and differentiation as well as for leveraging private investment.
\end{abstract}

Keywords: crisis, innovation, R\&D, investment.

\section{Introduction}

Manufacturing is the activity to make goods, usually on a large scale, through processes involving raw materials, components, or assemblies with different operations divided among different workers. Manufacturing encompasses equipment for materials handling and quality control and typically includes extensive engineering activity such as product and system design, modelling and simulation, as well as tools for planning, monitoring, control, automation and simulation of processes and factories. It is increasingly seen as a priority area of economic activity especially for economies that have been hit by the recent financial and economic crisis.

The paper aims to identify issues pertaining to manufacturing innovation in the framework of Horizon 2020. Smart policies will be required to link up R\&D and innovation strategies at regional, national and European levels and to offer needed incentives for growth and differentiation as well as to leverage investments towards the ambitious goal of countering Europe's de-industrialisation.

\section{Addressing the Challenges of Europe's Manufacturing}

The challenges for manufacturing in Europe can be summarised as in fig. 1: 


\section{Strengths}

- European mechanical engineering (machines, equipment \& systems industry)

- Industrial software (embedded software including factory automation + robotics, ERP + analytics, PLM software)

- High \& flexible automation equipment enabling mass customisation

- Sustainability as a driver

\section{Weaknesses}

- Despite strengths in industrial ICT, Europe's ICT industry is globally insignificant \& fragmented

- Lack of large integrators (e.g. OEMs offering system-level products rather than components)

- Incoherent trade/competition/industrial policies

\section{Opportunities}

- Concerns over climate change \& nuclear risks drive demand for sustainabilityconscious European technology

- Growing wealth of global consumers drives demand for customized quality products

- Manufacturing increasingly popular with policymakers

- Local capabilities enhanced by 3D printing, photonics-based equipment \& methods, micro-nano- \& bio-based materials, personal robotics, ICT infrastructures (e.g. Clouds)

\section{Threats}

- De-industrialisation: Manufacturing/engineering unpopular with large parts of society, outsourcing trends, low investment in R\&D\&I

- Lack of support for exporting SMEs

- Lack of incentives to skills development in STEM

Fig. 1. SWOT analysis of European manufacturing

Manufacturing accounts for around $16 \%$ of Europe's GDP. It remains a key driver of $R \& D^{1}$, innovation, productivity growth ${ }^{2}$, job creation and exports. $80 \%$ of innovations are made by industry. $75 \%$ of EU exports are in manufactured products. Each job in manufacturing generates two jobs in services. Since the beginning of the financial and economic crisis, however, EU employment in manufacturing has fallen by $11 \%$. The recent moderation of the recovery has kept employment levels in manufacturing low and the perspectives of a fast rebound remain rather weak. Over the last decade the

\footnotetext{
${ }^{1} 80 \%$ of private investment.

$23 \%$ on average vis-à-vis $1 \%$ of the economy between 2000-2007.
} 


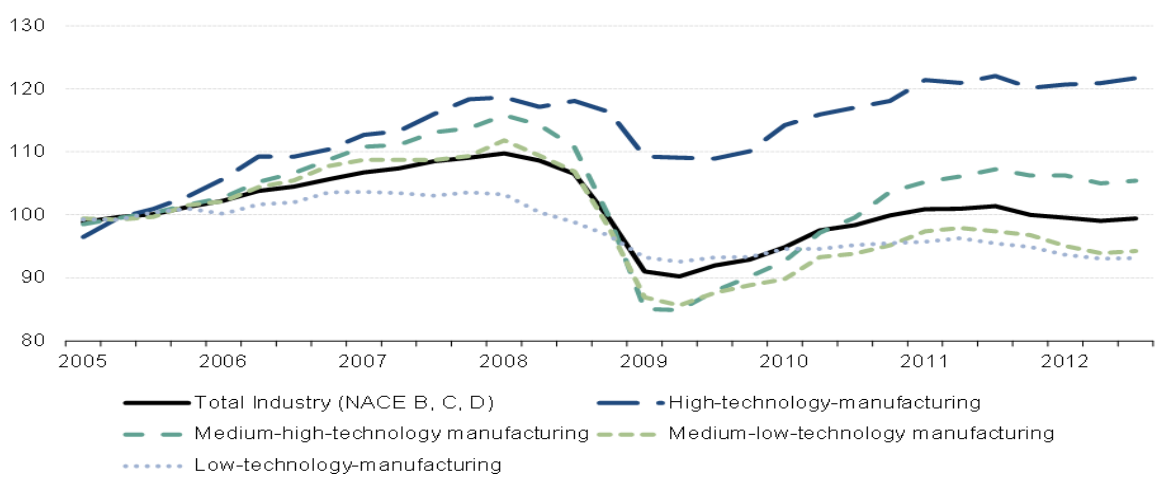

Fig. 2. Index of production for total industry and main technology groups in manufacturing, EU27, 2005-2012, seasonally adjusted (2005=100) - Source: Eurostat

share of manufacturing in EU employment and value-added has been declining. In 2011 it accounted for over $14 \%$ of employment and over $15 \%$ of total value added, representing $23 \%$ and $22 \%$ respectively, in the non-financial business economy.

As shown in fig. 2, the crisis has had severe consequences over manufacturing in Europe. However, high-technology manufacturing ${ }^{3}$ has performed better than the rest of the industry.

Recent econometric research ${ }^{4}$ points to the fact that a country's or a region's capacity to export products only few others can make is based on an accumulation of manufacturing knowledge and capability leading to its competitive advantage over others.

A recent World Economic Forum report on "The Future of Manufacturing" 5 highlights the key role of enabling technologies and infrastructures in enabling "manufacturing to flourish and contribute to job growth". As these are growing in importance and sophistication it becomes challenging to develop and maintain them.

At the beginning of this decade the European Union put forward Europe 2020, a ten-year growth strategy that aims at more than just overcoming the crisis that continues to afflict many of Europe's economies. It aims to address the shortcomings of the current growth model by supporting "smart, sustainable and inclusive growth" along five objectives ${ }^{6}$ : more employment, more investment in $R \& D$ and innovation,

3 High-technology manufacturing comprises aerospace, pharmaceuticals, computers, office machinery, electronics/communications and scientific instruments sectors with relative high R\&D expenditure on value added.

4 See "Complexity and the Wealth of Nations" in:

http: / / harvardmagazine.com/print/26610 ?page=all

and "The Art of Economic Complexity" in:

http: / / www nytimes.com/interactive/2011/05/15/magazine/

art-of-economic-complexity.html?_r=0

5 "The Future of Manufacturing. Opportunities to Drive Economic Growth", World Economic Forum Report, April 2012; "Special Report on Manufacturing and Innovation", The Economist, 19 April 2012; "Why Manufacturing Still Matters", New York Times, 10 February 2012; "Future Factories", Financial Times, 11 June 2012.

6 Europe 2020 strategy, see relevant documents under: http://ec.europa.eu/europe2020/index_en.htm 
attaining the triple-20 climate change/energy targets, better education and higher skills levels and finally by eliminating poverty and social exclusion.

The next EU Framework Programme for research and innovation, called Horizon $2020^{7}$, directly supports the policy framework of Europe 2020. It is due to start on 1 January 2014 and to run over seven years with a total budget of around 80 billion, according to the European Commission's proposal. The proposal is currently under debate in the

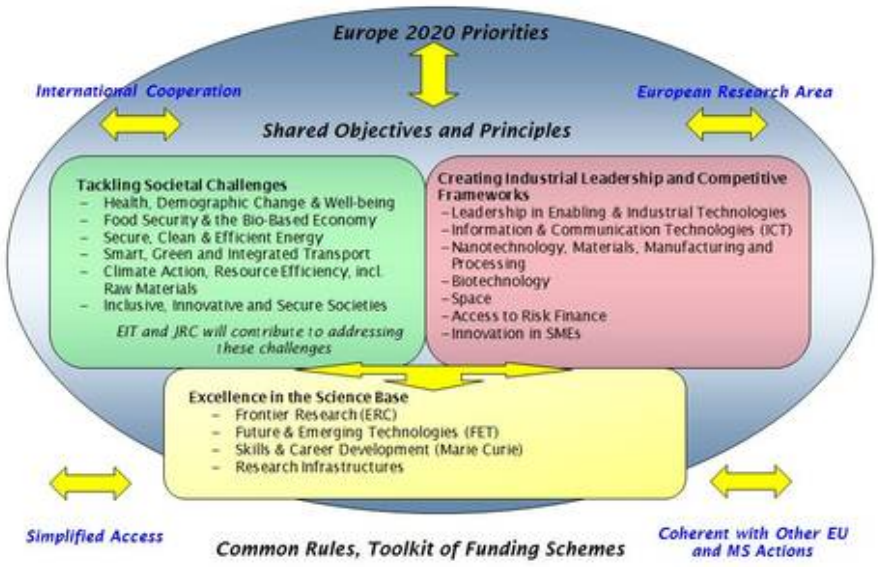

Fig. 3. The Horizon 2020 Framework Programme

European Parliament and the Council of the European Union. The proposed structure consists of basic priorities related to: (1) excellent science; (2) industrial leadership; (3) societal challenges (see fig. 3).

Compared to previous EU Framework Programmes Horizon 2020 will bring together research and innovation in a single programme, it will focus on multidisciplinary societal challenges European citizens face and it will aim to simplify the participation of companies, universities, and other institutes in all EU countries and beyond.

The programme's activities related to manufacturing are mostly concentrated in the activity area called "Leadership in enabling and industrial technologies". Key activities will focus on roadmap-based research and innovation involving relevant industry and academic research stakeholders.

In 2012 the Commission put forward an update of its Industrial Policy Communication $^{8}$ which supports a further 2020 objective which aims to reverse Europe's deindustrialisation: Industry to account for $20 \%$ of the EU GDP by 2020.

7 Horizon 2020: The EU Framework Programme for research and innovation, see relevant documents under: http: / / ec . europa. eu/research/horizon2020

8 "A stronger European industry for growth and economic recovery", $\operatorname{COM}(2012) 582$ final. 


\section{Towards Manufacturing Innovation}

\subsection{The Factories of the Future PPP}

The Factories of the Future initiative was launched as a public-private partnership (PPP) in 2009, constituting a EUR 1.2 bn part of the European Economic Recovery Plan?.

In total 98 projects were launched after three calls for proposals ${ }^{10}$ and 52 projects in the final call of 2012, currently under grant agreement negotiations. The projects represent research and technology development and innovation related activities that cover the full spectrum of manufacturing, from the processing of raw materials to the delivery of manufactured products to customers, across many sectors, covering both large-volume and small-scale production, dealing with matters such as supply chain configurations, virtual factories, material processing and handling, programming and planning, customer-driven design, energy efficiency, emissions reductions, new processing technologies, new materials, upgrading of existing machines and technologies, including many projects involving elements of, or wholly focused on, various uses of Information and Communication Technologies (ICT).

\subsection{High Performance Manufacturing}

There are also a diverse range of projects that are clustered under the theme of High Performance Manufacturing. Projects here focus on: production of high precision plastic parts; development of photonic device production capabilities; development of precision glass moulding processes; enhancing tool-making technologies for highprecision micro-forming; development of new manufacturing routes for micro- and nano-scale feature manufacturing; zero defect manufacturing; control of milling processes for thin-walled work-pieces; production of grapheme, etc. There are also projects investigating additive manufacturing and robotics for maintenance tasks applied to large scale structures. Consideration is also being given in some projects to modular reconfigurable production systems and the development of capabilities to customise products and to put in place the necessary manufacturing capabilities needed for customisation.

Impacts for this theme consist of improved dynamics for cutting processes, higher precision, and improved reliability during changing process conditions. But also evident are impacts in terms of lowering commissioning and ramp-up times, and

9 A European Economic Recovery Plan, COM(2008) 800 final, 26 November 2008, electronically available under:

http: / / eur-lex.europa.eu/LexUriServ/

LexUriServ.do?uri=COM:2008:0800:FIN:en:PDF

10 Interim Assessment of the Research PPPs in the European Economic Recovery Plan, Brussels, 2011, electronically available:

http: //ec.europa.eu/research/industrial_technologies/pdf/

research-ppps-interim-assessment_en.pdf 
avoiding investments in new production machinery through enhancing re-usability of manufacturing technologies and systems, and extending the life of machinery through add-ons and upgrades. Some developments are evidently also enabling, in the sense that once the processes and associated technologies are developed they will enable those who purchase them to engage in their own innovation (additive manufacturing is one example of this).

\subsection{Sustainable Manufacturing}

Under the theme Sustainable Manufacturing, projects, also diverse in character and focus, are dealing with matters that have relevance to creating a more environmentally responsible approach to manufacturing. Here there are projects that are also addressing customisation issues, with one example being customised clothing that allows the customer to choose more environmentally benign materials. There are also other projects dealing with customisation with an eco-dimension, delivering environmental assessment tools while also providing web-based access to support the customisation process. Work is also being undertaken on the development of the supporting manufacturing and supply chain infrastructure necessary for a shift away from large volume standardised products, to small scale production of customised products. Other projects are working on topics such as: environmental footprint reduction for metal formed products; resource efficient manufacturing systems; waste energy recovery; eco-efficient firing processes; use of predictive maintenance to achieve optimal energy use; condition and energy consumption monitoring; harmonisation of product, process and factory lifecycle management, etc.

For projects with a sustainability focus, impacts tend to be with respect to reductions in costs, energy consumption, emissions, and material wastage, but also in terms of increased availability of processes and machines and improved plant efficiencies. Also evident are impacts such as better understanding of customer needs, reduced time to market, reductions in delivery times, reduced transportation costs, and more time and cost effective customisation. Also, improved decision-making as a result of more in-depth understanding of environmental impacts is an impact. Potentially, the capability to produce customised products cost-effectively on a small scale could result in a shift away from large expensive centralised production facilities (with their associated significant transportation-driven carbon emissions) to more local production closer to the point of sale.

\subsection{ICT for Manufacturing}

In the domain of ICT there are projects that focus on platforms, which can be considered as the hardware, system architectures and software, necessary to undertake a range of related tasks. Typically these platform projects are focused on specific interests such as: manufacturing information and knowledge management; supply chain configuration; creation of virtual factories assembled from multiple independent factories; and collaborative engineering. But there are also ICT projects addressing 
simulation, game-based training, support for end-of-life material recovery and remanufacturing, advanced robotics, energy efficiency monitoring, laser welding, etc.

Impacts by these projects include reduced costs, accelerated product and process engineering, greater flexibility, improved quality, better equipment availability, reduced use of consumables, lower energy consumption, etc. ICT is also in many of these projects more than just a technology, but also an enabling technology in that it has the potential to bring about changes in method, procedures, or to open up new possibilities. Some of the targeted impacts in this respect include developing specific software targeted at SMEs to take account of their specific constraints (for example, limited time and expertise). Another enabling impact is greater flexibility, both in terms of capabilities of specific machines and processes, but also in the capability to redeploy these in new configurations (factory layouts), to meet changing demands. In some of the ICT projects it is also possible to see consideration being given to addons and upgrades to existing machines and systems, which will help to improve the performance of existing equipment and to extend its useful life.

\subsection{Lessons from Four Years of Operation of the PPP}

In a report from a recent workshop ${ }^{11}$ involving all Factories of the Future projects launched under the first three years of the PPP's operation, the following observations were made.

Overall the Factories of the Future PPP has been a good initiative to generate a family of industry-related projects. Industry participation has increased to over $50 \%$ (30 \% SME participation). The PPP also helps to create a broader spectrum of research projects, addressing higher levels of technology readiness than basic research projects. For SMEs, who need solutions designed to fit their constraints (time, money, expertise) the PPP proves to be very valuable if sufficient consideration is given to projects that address these constraints.

Academia and research institutions participate in these projects, and for them there is an added value of being able to provide students with research projects driven by a clear industrial need, and also to provide contacts for these students with industry personnel and facilities. However, greater emphasis needs to be given to the research training potential of those PPP projects, to maximise the benefits for young researchers that come from working with industry. Development of manufacturing oriented Living Labs may have a role to play here in enhancing industry-academia interactions.

Projects address a wide range of technologies and issues relevant to enhancing the competitiveness of European manufacturing, and many potential impacts are evident in these projects. The challenge is how to turn impacts into tangible business benefits in the marketplace, which requires more focus on business and market issues. Projects

11 Impact of the Factories of the Future Public Private Partnership, Workshop Report, 22 April 2013, available electronically:

http: / / ec. europa.eu/research/industrial_technologies/pdf/

fof-workshop-report-11-12-032013_en.pdf 
are beginning to realise that a much stronger business and market focus is needed within the PPP, and they have identified activities in this area that could form the basis for clustering.

One of the great benefits of clustering is bringing different perspectives and expertise together, which points towards clustering that is based on diversity, rather than similarity. However, some balance between the two does need to be achieved. Some clustering activities are relatively easy to do, such as joint dissemination, or collective contributions to standardisation. Some activities however are more challenging, such as addressing business and market related issues, and also sharing results, which raises confidentiality and IPR related issues. Yet in terms of that which will have most impact for projects and the PPP as a whole, is the hard-to-do clustering that is likely to be most effective. Projects have identified that clustering which addresses business and market related matters can be of great importance with regard to helping to take results to the market. Self-evidently, difficulties such as coping with IPR issues and guidance on how best to undertake challenging clustering activities will be needed, but none of the problems that people raise to undertaking this type of clustering are insurmountable.

\section{Conclusions}

$\mathrm{R} \& \mathrm{D}$ and innovation activities under a public-private partnership scheme are a way forward for Europe's industry to address effectively the challenges of manufacturing innovation.

It will be essential to address new and promising technologies such as 3D-printing, model-based controls, composites and nano-based materials as well as industrial ICT to stimulate innovation in manufacturing and offer a competitive advantage to European enterprises.

\subsection{Develop and Implement 'New Manufacturing'}

Manufacturing is likely to evolve along three paths ${ }^{12}$ :

- On-demand manufacturing: Fast-changing demand from internet-based customers requires mass-customised products. The increasing trend to last-minute purchases and online deals requires from European manufacturers to be able to deliver products rapidly and on-demand to customers. This will only be achievable through flexible automation and effective collaboration between suppliers and customers.

- Optimal (and sustainable) manufacturing: Producing products with superior quality, environmental consciousness, high security and durability, competitively priced. Envisaging product lifecycle management for optimal and interoperable product design, including value added after-sales services and take-back models.

12 http://www.actionplant-project.eu/images/stories/vision.pdf 
- Human-centric manufacturing: Moving away from a production-centric towards a human-centric activity with greater emphasis on generating core value for humans and better integration with life, e.g. production in cities. Future factories have to be more accommodating towards the needs of the European workforce and facilitate real-time manufacturing based on machine data and simulation. 'Assisted working' should aid an aging workforce to leverage skills and knowledge effectively for the creation of innovative products.

\subsection{Continue the Structuring of Europe's Industrial Landscape}

The introduction of the Recovery Plan PPPs has contributed to this structuring effect by encouraging strategic thinking in terms of roadmapping, financial commitment as well as 'impact-driven' thinking among European industrial players. The formation of industrial research associations such as EFFRA ${ }^{13}$, in the case of the Factories of the Future PPP, alongside the four annual calls for proposals in this domain has had a significant structuring effect in synergy with the European Technology Platforms which in the case of MANUFUTURE has also led to the creation of national Technology Platforms in almost every EU Member State and beyond.

\subsection{Leverage the Benefits of Advanced Manufacturing across the EU}

Smart specialisation in advanced manufacturing is a way forward through identification and strengthening of competitive advantages existing in EU regions (e.g. skills, R\&D capability, industrial output, ICT infrastructure and complementarities to neighbouring regions). Whilst national and European R\&D programmes in the past have been focusing on developing new and powerful technologies, they lacked however the incentives and the institutional setup to encourage their dissemination and take-up across sectors, across countries and regions. Roadmap-driven R\&D and innovation partnerships (PPPs) could play a significant role in bringing together the relevant stakeholders (industrial firms, academia, standardisation bodies, funding bodies (including VC investors) and public administrations at all levels) to generate market impact and thus strengthen Europe's industrial capability.

In Europe, it seems that entrepreneurial skills are required to drive results exploitation forward, from EU funded projects, via national/regional level demonstrators (pilot plants), to cross-fertilisation and uptake in different industrial sectors ${ }^{14}$.

13 The European Factories of the Future Research Association (EFFRA), http: / / www. effra.eu

14 José Carlos Caldeira, From Research to Commercial Exploitation - The Challenges Covering the Innovation Cycle, presentation at Advanced Manufacturing Workshop, Brussels, 27 May 2013, electronically available here: http://ec.europa.eu/enterprise/ policies/industrial-competitiveness/amt/public-hearingsworkshops/index_en.htm\#27.05.2013 


\section{Disclaimer}

The views outlined in this publication are the views of the author alone and do not necessarily reflect the official position of the European Commission on this matter. 